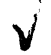 \\ SURGERY OF THE ADRENAL GLAND
}

By SELWYN TAYLOR, M.CH., F.R.C.S.
Surgeon, King's College Hospital and Belgrave Hospital for Children. Surgeon and Lecturer in Surgery at the $e_{\mathrm{D}}^{\mathrm{D}}$ Postgraduate Medical School of London

The surgery of the adrenal gland is a subject which is expanding rapidly at the present time. Kendall's work on the identification of adrenal cortical hormones, leading in recent years to a plentiful supply of cortisone, has made such operations relatively safe. In addition, increased knowledge about the physiology of the gland has put this branch of surgery on a more rational basis. This article deals primarily with the surgical treatment of Cushing's syndrome and phaeochromocytoma, but a few introductory remarks are given on the physiology of the normal adrenal and in Fig. I will be found a simple plan of the disorders which may affect this organ and call for surgical correction. It must be stressed that treatment can only be carried out with any hope of success where there is close co-operation between physician, surgeon and biochemist, and they should share the pre- and post-operative management of the patient.

The adrenal gland is composed of an outer yellow cortex and an inner reddish brown medulla. During foetal life the medulla arises from similar embryonic tissue to that which gives rise to the sympathetic nervous system and when fully developed this part of the adrenal gland elaborates two active hormones, adrenaline and nor-adrenaline. The medulla is not essential for the maintenance of life and similar tissue made up of chromaffin cells can be found in other sites. Tumours composed of such cells have been reported in relation to the abdominal aorta and occasionally in the neck and mediastinum. The cortex is essential to life and produces hormones controlling carbohydrate, protein and electrolyte metabolism. The cortex develops from tissue adjacent to that which forms the testis or ovary, and adrenal cortical dysfunction is often associated with changes in the sex organs of the individual. Total destruction of both adrenals leads to Addison's disease and death, but the patient can be kept alive by the administration of added salt in the diet and desoxycorticosterone acetate (DOCA), a synthetic cortical salt hormone. In addition cor- tisone may be given and leads to a greater sense of well-being and corrects any tendency to hypo 3 glycaemia.

\section{Surgical Anatomy}

The adrenal glands are relatively inaccessibleñ but a needle thrust through the postero-medialo extremity of the IIth intercostal space will trans-o fix the gland. At birth the adrenals are relatively much larger than in the adult and they are alsob more prominent in childhood than in later life. The maximum weight of the normal fresh adrenaleo in the adult is probably about $7.5 \mathrm{gm}$. (Priestlez).

The right adrenal sits on the supero-medial pole of the right kidney, separated from it by a tine layer of fascia and sometimes fat, but contained within Gerota's fascia. It is for this reason that airo introduced just above the iliac crest (Cope and Schatzki) or in front of the sacrum (Blackwood) will rise and surround kidney and adrenal and makeō radiological portrayal possible. The antero-medial relation is the inferior vena cava and this vein is bared when the right adrenal is excised. Anteriorly: the liver is in contact with this gland and it will be? clear from the description that the right adrenal is difficult to approach from the abdomen and less amenable to surgical excision by any route than the gland on the left side.

The left adrenal bears a similar relation to the kidney as that on the right and lies posterior to the? lesser sac, which separates it from the stomach $\frac{D}{0}$ Inferiorly it is in contact with the pancreas, especially the upper border of the latter and the splenic artery which is running along it.

The adrenal is a very vascular organ and bleeds freely when cut. Its vascularity is probably only second to that of the thyroid. Each gland receives three small arteries which are by no means easy tơ define at operation as they vary much in size. The vein is single, by far the most prominent vessel and ${ }^{+}$ capable of being identified at operation. It usually leaves from a small cleft in the hilum of the gland $\underset{\times \mathbb{D}}{ }$ that from the right adrenal draining into the in $\frac{O}{\mathbb{D}}$ 
ADRENO-GENITAL SYNDROME

1. In uterine life produces pseudohermaphrodite

2. before puberty produces infant Hercules, precoctous sex, dwarf.

3. In adult females produces virilism. occurs rarely in males, feminising.

17 keto-steroids increased in urine increase of nitrogen and sex hormones

CUSHING'S SYNDROME

Diabetes, insulin resistant. Hypertension, headaches.

Thin, red, bruisable skin

Obese abdomen and moon face.

osteoporosis: Buffalo hump.

17-keto-sterolds often normal
gluco-corticolds increased urine

increase of gluco-corticoid

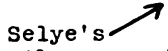

Alarm reaction

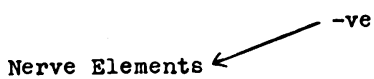

GANGLIONEUROMA
NEUROBLASTOMA

Right-sided, Pepper.

Left-sided, Hutchison.

.

ferior vena cava, that from the left into the left renal vein, passing down behind the body of the pancreas to reach it. A knowledge of the position of this vein is essential and the first step in practically all operations on the adrenal is to secure this vessel.

\section{Surgical Technique}

It is not surprising when one considers the relative inaccessibility of the adrenals, that a wide variety of different surgical approaches has been devised for their exploration. These operations are for the most part variants of three different routes, namely the anterior or transperitoneal approach, the lateral or lumbar incision, and the posterior route. Each has its own advantages and disadvantages which have to be carefully weighed in considering the treatment of a particular patient.

The anterior or transperitoneal approach can be carried out through' a long paramedian incision or preferably a supra-umbilical transverse incision. It has the merit of permitting inspection of both adrenals at one operation although it may be difficult to get adequate exposure of the gland on the right side. It also permits a thorough examination of the abdomen and a search for ectopic adrenal tissue and an ovarian tumour. The main drawback is that if it is used in an adult with Cushing's syndrome, the great obesity makes a satisfactory laparotomy difficult and under such circumstances it is unlikely that the right adrenal will be adequately exposed. This route is ideally suited to the exploration of the adrenals in infants and children and is also satisfactory for the removal of a phaeochromocytoma in adults.

The lateral or lumbar approach is used with various modifications by many surgeons; Walters has successfully performed a great many adrenalectomies by this route. The patient lies in the lateral position on the operating table, the kidney is exposed through an oblique incision and the adrenal is then brought into view by downward traction on the kidney. A careful dissection is made of each aspect of the gland since it may have extensions that are not apparent on looking at its presenting surface. If both adrenals have to be exposed it is necessary to close the wound, turn the patient and make a second incision on the opposite side.

An interesting variation of this approach, involving opening the pleura, has been described by Grimson. The left side is usually done first as the liver underlies the right diaphragm. The $\mathrm{I} I \mathrm{th}$ rib is excised from angle to costal cartilage, the pleura opened and the diaphragm retracted. The diaphragm is incised radially without opening the peritoneum and the adrenal sought in the retroperitoneal fatty tissue. A second radial incision in the anterior part of the diaphragm permits the 
hand to be introduced into the peritoneal cavity for palpation of the abdominal and pelvic organs. Grimson claims that the right adrenal can be palpated by this route but a note of warning should be sounded here. It is not possible to exclude the presence of an adrenal cortical tumour by blind palpation of the area in which the adrenal lies. It is always necessary to expose the gland to direct vision. The author has seen a surgeon experienced in adrenalectomy make a careful abdominal palpation of the adrenals at post-mortem in a patient who had died from Cushing's syndrome. No tumour could be felt but one was disclosed about $5 \mathrm{~cm}$. in $\mathrm{d}$ ameter when the adrenals were brought into view. Grimson recommends approaching the right adrenal through a similar transpleural route. The inferior vena cava is well visualized but the liver precludes a satisfactory exploration of the abdominal cavity.

The lumbar route is most useful in patients with Cushing's syndrome, especially when they are fit enough to be turned and both sides explored during one anaesthetic. It can also be employed when two operations are to be performed at two weeks' interval.

The posterior route should only be used when the operating table permits the patient to be acutely flexed, lying prone, the so-called jackknife position. When this is done both sides can be exposed at one operation which is convenient where Cushing's syndrome exists without a tumour, for it will then be necessary to inspect both adrenals before beginning any resection. Excision of the I2th rib can be used, or it may be dislocated upwards (Broster). The author's preference is for an oblique incision which starts over the neck of the 12th rib and passes outwards and downwards more obliquely than in Young's (1936) operation. Where there is a gross amount of fat, a not uncommon finding in adreno-cortical dysfunction, the help of a skilled assistant who can apply just the right amount of traction on the kidney is invaluable.

\section{Cushing's Syndrome}

This term will be reserved here for those patients who present with a striking clinical picture of complex symptomatology (see below). The term Cushing's disease can conveniently be used to describe those in whom the same clinical picture is associated with a basophil adenoma of the pituitary (Kessel quoted by Albright). Whether a pituitary tumour is present as Cushing (1932) described or not, there is always either an adrenal cortical tumour or hypertrophy of adrenal cortical tissue associated with this condition and surgical treatment consists of an attempt to correct this hypercorticism. Cushing himself stated that the symp- toms ' in all probability are secondarily ascribable to a hypersecretory influence of adrenal cortex even in the absence of any histologically appreciable abnormality' so that it is not without reason that the eponymous title for the disease is retained.

The pathological findings in Cushing's syndrome are either hyperplasia or hypertrophy of the adrenal cortices or a tumour of the adrenal cortex. Some patients will also show a basophil adenoma and Crooke's changes in the anterior pituitary. Rarely an arrhenoblastoma of the ovary may produce a similar clinical picture. Most rarely, only four cases have been reported (I93I, I933, 1949), a carcinoma of the thymus accompanies Cushing's syndrome.

The syndrome is much commoner in women than men and clinically there is:

1. Great obesity of the abdominal wall and trunk which may show striae, and of the face which becomes ' moon like.' A cervico-thoracic fat pad presents a ' buffalo' appearance.

2. The skin is thin, complexion ruddy, acne common and there is an accompanying increased susceptibility to bruising.

3. Muscle weakness.

4. Diabetes which is mild and resistant to insulin.

5. Osteoporosis, especially of the spine.

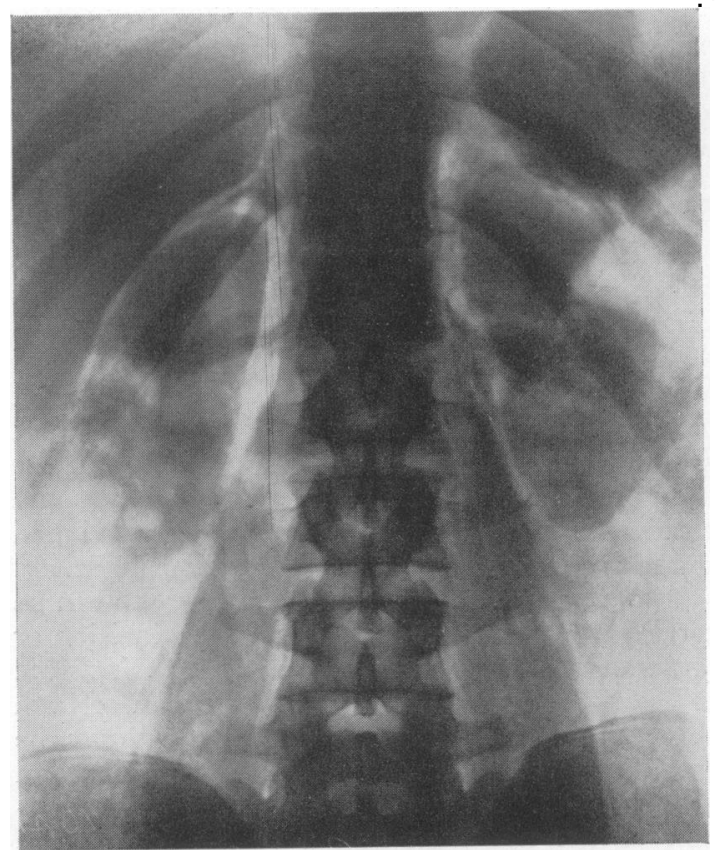

FIG. 2.- Straight $\mathrm{X}$-ray after air insufflation by the method of Cope and Schatzki. The patient was a pseudo-hermaphrodite. The picture shows adrenals which are apparently normal. (H.H. ro69I) 
6. Amenorrhoea or impotence. The author has seen two patients who presented in the gynaecological department complaining of infertility.

7. Hirsutism with normal or only slightly increased urinary excretion of 17 -ketosteroids. The gluco-corticoids are usually increased in the urine.

8. Hypertension, degenerative arterial disease, headache and mild polycythaemia.

9. Mental depression and personality changes.

A diagnosis of Cushing's syndrome having been made, it is necessary to decide what form of adrenal cortical abnormality is present, i.e. tumour or bilateral hypertrophy. A straight X-ray may on rare occasions demonstrate a tumour. If, however, air can be introduced around the adrenals, $\mathrm{X}$-rays are much more likely to demonstrate an abnormality. The original technique for obtaining such pictures was to inject air or oxygen in the lumbo-sacral angle (Carelli, I921; Rosenstein, I92I), but the danger was that the kidney was occasionally punctured, a haematoma formed and nephrectomy was required. In I939, Schatzki and Cope described a much safer procedure in which the air was introduced via a needle inserted at the

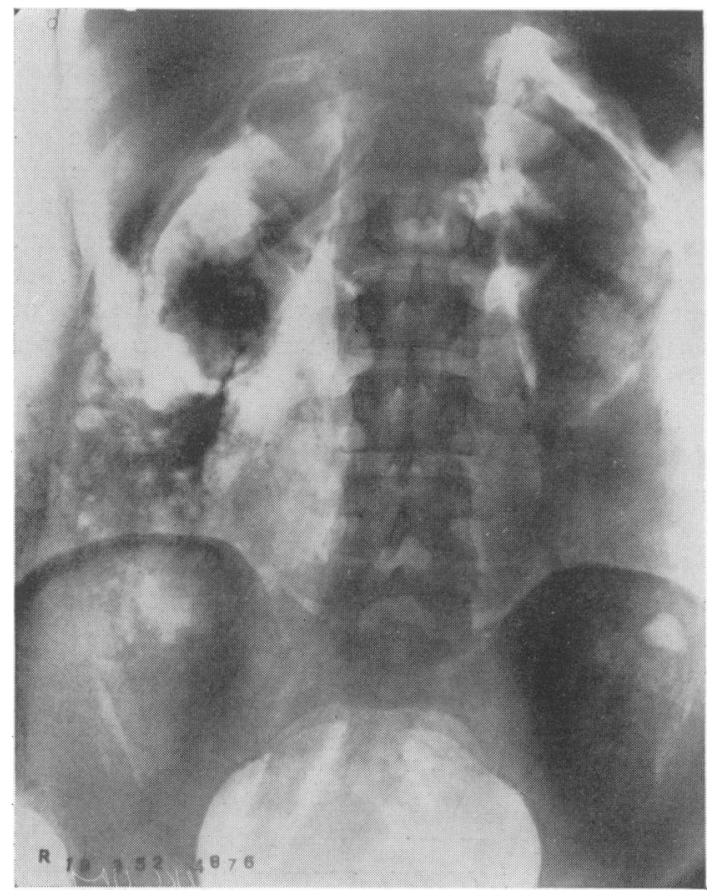

FIG. 3.-Straight X-ray after air insufflation by the method of Blackwood. The patient presented with Cushing's syndrome and the picture shows a tumour of the right adrenal which was subsequently removed. (H.H. 129460) angle between the erector spinae mass and the iliac crest. Fig. 2 was obtained using this method. More recently (I95I) Blackwood has described a technique of perirenal pneumography in which the air is introduced into the hollow in front of the sacrum by a needle inserted just in front of the coccyx, $400 \mathrm{cc}$. of air are injected on each side and $\mathrm{X}$-rays taken after the patient has walked about for 20 minutes. Fig. 3 showing a tumour of the right adrenal cortex of a woman with Cushing's syndrome was obtained by this method. Tomography is sometimes of use in obtaining better detail of the adrenals. Fig. 4 shows a picture obtained by such a method. When no tumour can be demonstrated radiologically it may still be impossible to say whether or not the adrenals are abnormal in appearance, however good the X-rays.

\section{Pre-Operative Preparation}

Two 24 hour specimens of urine are sent for 17ketosteroid assay since if subtotal adrenalectomy has to be performed, the amount of cortical tissue remaining can be gauged after three months by the amount of reduction in 17 -ketosteroid excretion. The serum potassium and sodium are measured on two days as a base-line and to guide subsequent

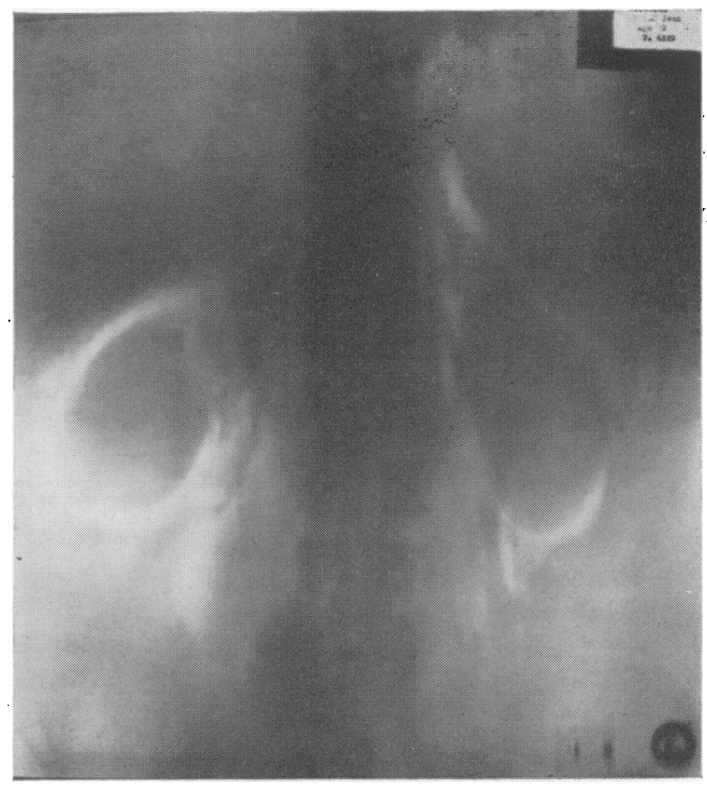

FIG. 4.-Tomograph after air insufflation by the method of Blackwood. The patient presented with Cushing's syndrome and the picture shows hypertrophy of both adrenals. The patient was treated by subtotal adrenalectomy. (K.C.H. T4229). 
electrolyte replacement. The patient is given 200 mg. of cortisone by intramuscular injection daily for two days immediately before the operation. This is slowly absorbed and acts as a depot. Cortisone is given by mouth in the post-operative period as oral cortisone is rapidly absorbed.

\section{Operation}

The choice of route has already been discussed. If a tumour is known to exist on one side it is only necessary to explore that adrenal and remove the tumour. In all other patients both adrenals have to be seen before embarking on any resection. Subtotal adrenalectomy consists of excising all of one adrenal and seven eighths of the other, and it can be done safely if cortisone is available. If the operation is done in two stages it is usual to embark on the partial removal of one adrenal first. At the second operation the viability of the remaining fragment of adrenal is checked before total excision of the opposite gland.

In total excision of an adrenal it is first necessary to define and tie the vein which leaves the hilum. After this the gland is carefully freed by blunt dissection and gently removed. Adrenal tissue is friable and it is easy to tear it and leave fragments behind which have remarkable powers of regeneration. Where a subtotal resection is done, it will be found most convenient first to place fine linen mattress sutures with a curved round-bodied needle isolating the portion that is to be left. The removed adrenal tissue should be cut open with a knife so that its identity may be established by revealing the distinctive folded cortex overlying a thin darker streak of medulla. It is useful to have a small balance in the operating theatre upon which the removed tissue can be weighed while it is still fresh and moist.

If the inferior vena cava is injured during removal of the right adrenal the bleeding can be controlled by Walters' method of packing the wound with gauze, which can be removed safely after 24 hours.

During the removal of the greater part of the second adrenal the blood pressure may fall to low levels. When the systolic pressure falls below I00 $\mathrm{mm}$. Hg. it can be brought up again by an infusion of nor-adrenaline and it is convenient to keep the needle in place in the vein after the patient returns to the ward and to run in the fluid whenever the pressure falls below this level. As a further restorative measure during the operation, up to $200 \mathrm{cc}$. of an aqueous adreno-cortical extract (eucortone) can be given intravenously. If a malignant adrenal cortical tumour not confined to the gland is found, it is unlikely that any attempt at surgical excision will alter the course of the disease.

\section{Post-Operative Care and Complications}

The blood pressure is maintained as described above and cortisone given by mouth as soon as it is possible; $200 \mathrm{mg}$. is given in the first 24 hours, roo mg. daily thereafter for four days and a $\overrightarrow{\bar{N}}$ further $50 \mathrm{mg}$. daily for four days. More prolonged adrenal replacement therapy is only given when there are signs of adrenal insufficiency, such as nausea, prostration and severe anorexia. Adrenocorticotrophic hormone (ACTH) may be injected subsequently to stimulate the patient's remaining adrenal tissue.

Daily estimations of serum sodium and potassium are a good guide to electrolyte replacement and a low sodium level is treated by giving coated tablets of salt up to $5 \mathrm{gm}$. a day. These may cause nausea but do not usually have to be given for long. Most patients feel marked muscle weakness at first and need especially energetic breathing exercises to prevent chest complications.

Before cortisone was available, the most dreaded complication was the sudden collapse of the patient whose blood pressure fell to an undetectable level. Often this shocked state did not respond to transfusion and death followed. When there has been adequate cortisone cover this is a rare occurrences In the later post-operative period, overt signs of Addison's disease may appear and some patients. require treatment for this indefinitely. Since most failures in the past to obtain a remission in Cushing's syndrome were due to inadequate removal of adrenal tissue, it is probably better to run the risk of removing too much, now that adequate replacement therapy is possible. About $25 \mathrm{mg}$. cortisone daily are necessary for maintenance. It must not be forgotten, however, that the price of cortisone is still of the order of $£^{6}$ to $£ 7$ per gramme.

Fat necrosis is a common complication but it is also seen in patients dying of Cushing's syndrome who have never had an operation (Kepler).

Acute pancreatitis has been described (Priestley) as a cause of death following adrenalectomy, and a pancreatic cyst may develop as a result of injury to the tail of the pancreas in excising the left adrenal. This complication occurred in a patient operated upon by the author, but after evacuating the cyst it has not recurred. The most disappointing end-result is a recurrence of the original signs and symptoms of Cushing's syndrome and further operation may be more difficult. Walters has, however, successfully re-operated upon one of his patients and obtained a second remission, but at the price of adrenal insufficiency. Patients who develop the latter complication usually show the typical skin pigmentation of Addison's disease. 


\section{Phaeochromocytoma}

A phaeochromocytoma is a tumour composed of cells similar to those found in the adrenal medulla and most of these tumours arise in the medulla itself, though occasionally they are found elsewhere.

Phaeochromocytomata appear typically in young adults of either sex, about ro per cent. of these tumours are bilateral and some ro per cent. are malignant. They produce a secretion which may be made up from 50 to 90 per cent. of noradrenaline and the remainder of adrenaline. The different effects which these two hormones exert is important. Adrenaline acts as an overall vasodilator but causes a raised blood pressure through increasing the cardiac output. Nor-adrenaline on the other hand acts as an overall vasoconstrictor with little direct effect upon the heart.

\section{Signs and Symptoms}

The main manifestation of a phaeochromocytoma is the production of paroxysmal attacks of hypertension, when the systolic pressure may rise to $300 \mathrm{~mm}$. Hg. and the diastolic to $200 \mathrm{~mm}$. Hg. The patient goes pale and sweats, may have a violent pulsating headache and sometimes collapses. Liver glycogen is mobilized during an attack, the blood sugar rises and so does the basal metabolic rate (B.M.R.). The attacks may recur over a period of years or they may become rapidly more frequent and more severe, terminating fatally after a few months.

Patients may present with varied symptom complexes during attacks. Palpitation is common, blurring of vision and choking sensations are also sometimes encountered. There may be extreme pain in chest, back or limbs and occasionally vomiting and diarrhoea.

The diagnosis is confirmed when pressure over one loin, whether there is a palpable tumour or not, excites an attack. Often the patient knows on which side the lesion is situated. Sometimes a chronic hypermetabolic state develops. There may be great difficulty in diagnosis when the patient presents with symptoms of an acute abdomen with severe abdominal pain and shock. Vomiting, headache, palpitation and sweating accompanying this clinical picture (Gilliland and Daniel) may lead to the correct diagnosis.

\section{Diagnosis}

An intravenous pyelogram may show one kidney to be displaced downwards by a tumour. Air studies (see above) may demonstrate a tumour but are not without risk and should be avoided if possible. The B.M.R. may be elevated and some patients with phaeochromocytoma have been subjected to thyroidectomy in error. A variety of tests has been devised to aid diagnosis, depending either on exciting an attack or on lowering the blood pressure during one. The most difficult diagnostic problem is to differentiate between essential hypertension and a persistently raised blood pressure due to a phaeochromocytoma.

Roth and Kvale proposed a test in which 0.025 to $0.05 \mathrm{mg}$. of histamine was injected intravenously and serial blood pressure readings were made. In the presence of a phaeochromocytoma the pressure reached a high peak in two minutes.

The intravenous injection of a 2 per cent. solution of benzodioxane (piperidyl methyl benzodioxane) which is adrenolytic will lower the blood pressure if its elevation is due to adrenaline (Goldenberg et al). The drug acts as a pressor in essential hypertension so is not without risk. Intravenous dibenamine ( $N, N$ - dibenzyl - beta chloroethylamine hydrochloride) (Spear) is another adrenolytic agent with a much more prolonged effect, up to 24 hours. Other tests have been described using tetraethylammonium bromide and mecholyl chloride, but it should be pointed out that so far none of these pharmacological aids to diagnosis has been found consistently reliable. Probably' the histamine test is the most useful diagnostic aid in patients who have paroxysmal attacks and benzodioxane for those who present with sustained hypertension. The most reliable method for diagnosing phaeochromocytoma is to determine the urinary concentrations of adrenaline and nor-adrenaline (Engel and von Euler, r950; Hamilton et al., 1953). Unfortunately the method is elaborate and only available in specially equipped laboratories.

\section{Surgical Technique}

The first successful excision of a phaeochromocytoma was by C. H. Mayo in 1927. Since about Io per cent. of these tumours are multiple and have been described lying some way distant from the adrenals, especially in relation to the abdominal aorta, the best approach is an anterior one through the abdomen.

Handling the tumour leads to severe hypertension and therefore the greatest gentleness is essential during operation. No manipulation of the tumour should be done until the vascular pedicle has been secured. The commonest cause of death, and excision of a phaeochromocytoma carries a high mortality, is due to the severe shocklike state that may follow the removal of the tumour. This condition may not be reversed even when large amounts of adrenaline are injected intravenously. The discovery that many of these tumours contain a high percentage of noradrenaline has led to a solution of this drug being given by slow intravenous infusion throughout the operation. As soon as the blood pressure falls the 
nor-adrenaline is run in more quickly and after operation the needle is kept in the-vein and further amounts of nor-adrenaline run in as required until at least 24 hours after operation. By this means many patients can be tided over hypotensive episodes which might otherwise prove fatal.

On those rare occasions when the presence of a tumour in both adrenals makes a bilateral operation necessary there is a risk that the patient may develop symptoms due to deprivation of cortical hormones, for part of the adrenal cortex may be destroyed by pressure atrophy, and a further amount devascularized during the operation. For this reason cortisone should be available in case it is required and used as described above; following the surgical treatment of Cushing's syndrome. It is not necessary to give it routinely as described by some authors. In those patients who survive the operative removal of a phaeochromocytoma the end-result is excellent and they are completely relieved of their hypertensive attacks. Only the degenerative changes which may have been produced in the cardiovascular system by the raised blood pressure remain.

\section{BIBLIOGRAPHY}

ALBRIGHT, F. (1942-43), Harvey Lecture Series, 38, I 23.

BLACKWOOD, J. (195 I), Brit. F. Surg., 39, 111 .

BROSTER, L. R. (I939), Ibid., 26, 925.

CARELLI, H. N., and SORDELLI, E. (1921), Rev. Assoc. med. $\stackrel{\complement}{\complement}$ Argent., 34, 18.

COPE, O., and SCHATZKI, R., (1939), Arch. Int. Med., 64, $1222 . \overline{\bar{G}}$

CUSHING, H. (1932), Bull. Fohns Hopkins Hosp., 50, 137.

ENGEL, A., and EULER, U. S. VON (1950), Lancet, ii, 387.

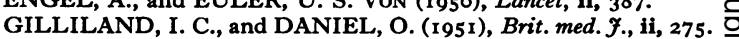

GOLDENBERG, M., SNYDER, C. H., and ARANOW, H. (1947), F. Amer. med. Ass., 135, 971.

GRIMSON, K. S., EMLET, J. R., and HAMBLEN, E. C. (1951), Ann. Surg., 134, 45I.

HAMILTON, M. H., LITCHFIELD, J. W. L., PEART, W. S., है and SOWRY, G.'S. C. (1953), Brit. Heart $\mathscr{F}$., in press. HUBBLE, D. (1949), Quart F. Med., 18, 133 .

KEPLER, E. J. (1950), 'Textbook of Endocrinology,' edited by R. H. William, with collaboration of Peter H. Forsham and $\vec{G}$ others. Philadel phia.

KEPLER, E. J. (1934), Proc." Staff Meet. Mayo. Clin., 9, I69.

KESSELL, F. K. (1936), Ergeb. d. inn Med. a. Kinderh, 50, 620 . LEYTON, O., TURNBULL, H. M., and BRATTON, A. B. (1931), F. Path. Bact., 34, 635 .

MAYO, C. H. (1927), Э. Amer. Med. Ass., 89, 1047.

PRIESTLEY, J. T., SPRAGUE, R. G., WALTERS, W., and SALASSA, R. M̈. (195 I), Ann. Surg., 134, 464.

ROSENSTEIN, P. Z. (1921), F. Urol., 15, 447.

ROTH, G. M., and KVALE, W. F. (1945), Am. F. Med. Sci., 2ro, N 653 .

SPEAR, H. C., and GRISWOLD, D. (1948), New England Y. Med., 239, 736 .

WALTERS, W. (1952), Lancet, i, 221.

YOUNG, H. H. (1936), Surg. Gynec. and Obst., 63, 179.

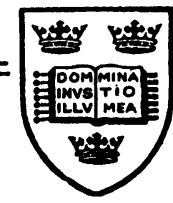

OXFORD MEDICAALUBLICATIONS

\title{
MAJOR ENDOCRINE DISORDERS
}

\author{
by S. LEONARD SIMPSON, M.D., F.R.C.P. \\ Consultant Endocrinologist to St. Mary's Hospital and to the Samaritan Hospital for Women. \\ Endocrinologist to Princess Louise Children's Hospital.
}

'The author is to be congratulated on the clarity and apparent ease with which he has tackled a difficult problem, and in particular for avoiding the long words that disfigure modern endocrinology. It is the best work of its kind we have seen in recent years.'-Clinical Journal.

'An admirable introduction and guide to a difficult subject.'-Postgraduate Medical Journal.

'Strongly recommended to anyone who has an interest in the subject of clinical endocrinology.'

- Journal of Bone and Joint Surgery.

Second Edition

574 pages

122 illustrations

42s. net

\section{OXFORD UNIVERSITY PRESS}

